\title{
Overcoming Innovation Deficiencies in Mexico: Use of Open Innovation through IT and Closed Innovation through IT by Small and Medium Enterprises
}

\author{
Mariana Giovanna Andrade-Rojas \\ Nanyang Technological University \\ mariana@ntu.edu.sg
}

Abhishek Kathuria

Indian School Business

abhishek_kathuria@isb.edu

\author{
Terence Saldanha \\ University of Georgia \\ terence.saldanha@uga.edu
}

\author{
Jiban Khuntia \\ University of Colorado Denver \\ jiban.khuntia@ucdenver.edu
}

\author{
Wai Fong Boh \\ Nanyang Technological University \\ awfboh@ntu.edu.sg
}

\begin{abstract}
Innovation is critical for development, especially in less-developed regions. We examine how Open Innovation through IT (an external collaboration approach) and Closed Innovation through IT (an internal collaboration approach) compare in helping small and medium enterprises overcome two challenges to achieve innovation: technological deficiency and government support deficiency. We hypothesize that Closed Innovation through IT is more important than Open Innovation through IT in helping firms overcome lack of technological abilities. We also hypothesize that Open Innovation through IT is more important than Closed Innovation through IT in helping firms overcome lack of government support through inter-organizational interactions and collaboration. Findings from a unique dataset of 389 small and medium enterprises in Mexico support our hypotheses. Our study highlights that small and medium enterprises can achieve greater innovation returns by orienting their IT-enabled innovation efforts in an open or closed fashion to address a specific deficiency.
\end{abstract}

\section{Introduction}

Innovation is critical for development, especially in developing regions like East Europe, Asia, Africa, and Latin America. Firms pursue innovation through two approaches: open innovation and closed innovation. In open innovation, firms collaborate with external stakeholders such as customers, suppliers, or competitors [1]. In closed innovation, firms "generate their own ideas and then develop them, build them, market them, distribute them, service them, finance them, and support them on their own" [1]. Closed innovation focuses on internal collaboration, whereas open innovation focuses on external collaboration.

Firms often use information technology (IT) to address challenges pertaining to innovation [2-4]. However, firms face a dilemma as to whether an open or closed approach to IT-enabled innovation is more suitable to address specific innovation challenges. A growing body of literature suggests that a closed approach to IT-enabled innovation plays a key role in product development, process design, innovation capabilities, and firm performance [5-8]. IT has evolved from enhancing efficiency to enabling innovation through several ways [e.g., 9, 10-13]. For example, knowledge capabilities driven by IT are an important enabler of closed innovation because IT helps firms capture, store, retrieve, and disseminate knowledge internally. Internal collaboration, crossfunctional integration enabled by IT can drive innovation [14]. Studies have also examined how IT facilitates open innovation [15]. For example, IT enables firms to pursue open innovation by enabling collaborative practices with external stakeholders [16, 17], facilitating inter-firm partnerships [18], enabling access to external knowledge sources [2, 19], and enhancing knowledge assimilation [11].

Despite extant and emerging research on IT and innovation, there has, to the best of our knowledge, been no study that examines and contrasts how using IT for closed innovation and IT for open innovation differently help small and medium enterprises overcome deficiencies that inhibit innovation. We fill this gap in this study by examining how Open Innovation through IT (an external collaboration approach) and Closed Innovation through IT (an internal collaboration approach) help small and medium enterprises overcome two challenges to achieve innovation: technological deficiency and government support deficiency. 
We define Open Innovation through IT as the extent to which a firm uses IT to collaborate for innovation with its external constituents such as market leaders, suppliers, competitors, and clients. Open Innovation through IT, as exemplified by interorganizational data access systems, helps a firm combine diverse complementary knowledge and resources from external stakeholders with the firm's knowledge and resources. However, Open Innovation through IT increases coordination costs since it requires collaboration with suppliers, customers, or complementors. Also, governing and collaborating with external stakeholders for innovation through IT can cause information overload [2]. In contrast, Closed Innovation through IT refers to the extent to which a firm uses internal information systems to promote innovation within the firm. Closed Innovation through IT helps firms address challenges of complexity and inefficiency when generating and developing their own ideas, thereby enabling firms to be self-reliant, instead of relying on external stakeholders for innovation. However, Closed Innovation through IT entails high dynamic adjustment costs for firms that can be detrimental to innovation [3].

In the case of Open Innovation through IT, the burden and costs of managing investments in IT for innovation can often be shared between a firm and its collaborators. Given the opportunities and challenges arising from Open Innovation through IT and Closed Innovation through IT, there is a need to study whether an open approach or a closed approach to IT-enabled innovation is more appropriate to address specific innovation challenges.

Two challenges to innovation are particularly salient in small and medium enterprises: technological deficiency and government support deficiency. First, technological deficiency refers to the extent to which a firm lacks technological abilities such as technological knowledge, technological skills of staff, and advanced technologies [20]. Second, many small and medium enterprises rely on government support for innovation because government support programs (e.g., subsidies, funding) enhance the extent of a firm's own innovative efforts or facilitate adaptation in a firm's innovation processes [21]. Government support deficiency refers to the extent to which firms cannot receive assistance from the government and its administrative units, which can include favorable policies, incentives, and programs. Technological deficiency and government support deficiency are salient challenges for innovation in small and medium enterprises in growing and transitional economies such as Mexico [22].

Accordingly, we pose the research question: How do Closed Innovation through IT and Open Innovation through IT compare in helping small and medium enterprises to overcome technological deficiency and government support deficiency to achieve innovation?

We hypothesize that since Closed Innovation through IT fosters the development of internal absorptive capacity through superior knowledge sharing practices in the firm, Closed Innovation through IT is more effective in overcoming the deleterious effects of technological deficiency on innovation. In contrast, we posit that since Open Innovation through IT bolsters external absorptive capacity through inter-organizational interactions and collaboration, Open Innovation through IT is more beneficial in reducing the harmful impact of government support deficiency on innovation.

Anecdotal examples show the practical importance of Closed Innovation through IT and Open Innovation through IT in small and medium enterprises. For instance, a medium sized manufacturing firm (anonymized for confidentiality) that had a deficiency in government support significantly improved its product manufacturing process by using IT to collaborate with its suppliers [23]. This IT-based collaboration enabled a supplier to suggest a revamp of the manufacturing process through automation. Due to this IT-enabled collaboration, the medium sized manufacturing firm mitigated the negative effect of government support deficiency on innovation by using IT in an open innovation fashion (Open Innovation through IT).

We test our hypotheses across a sample of 389 small and medium enterprises in Mexico. Our empirical analysis finds strong support for our hypotheses. This study makes two main contributions to theory. First, we help address a tension regarding Closed Innovation through IT and Open Innovation through IT by showing that they differ in the extent to which they help small and medium enterprises mitigate effects of technological deficiency and government support deficiency on innovation. Second, this study underscores that use of IT can help firms to overcome deficiencies in government support, thereby extending IT innovation literature to the institutional context related to government support for innovation.

Critically, this research has significant practical impact as innovation forms the basis for development in under-developed, or growing regions and such domains account for a large proportion of world population and economic output [22]. 


\section{Theoretical Development}

\subsection{IT and Innovation}

IT plays a key role in product development, process design, innovation capabilities, and firm operational performance [5-7, 24]. IT has evolved from enhancing efficiency to enabling innovation through several ways $[4,11,25,26]$. First, knowledge capabilities driven by IT are an important enabler of innovation. Second, collaboration, cross-functional integration, and teamwork enabled by IT can drive innovation [14]. Third, IT improves information processing and coordination capabilities, which in turn drive innovation.

The above are due to Closed Innovation through IT because they involve IT being used within the firm, studies have also examined how IT facilitates open innovation. IT enables firms to pursue open innovation by enabling collaborative practices with external stakeholders [17], enabling access to external knowledge sources [2], and enhancing knowledge assimilation [11]. IT promotes information processing and coordination across firms with their upstream and downstream partners. IT also facilitates innovation through crowdsourcing [27]. We next discuss the two types of absorptive capacity, which form the theoretical edifice for the study, along with the role of IT.

\subsection{Absorptive Capacity and IT}

We draw on theoretical concepts of two types of absorptive capacity, internal and external [28]. Absorptive capacity is defined as the "ability of a firm to recognize the value of new, external information, assimilate it, and apply it to commercial ends" [29]. Internal absorptive capacity encompasses "processes and capabilities underlying internal knowledge combination, recombination, transformation, exploitation, and assimilation", whereas external absorptive capacity refers to "management of exploration for new knowledge in the external environment" [28]. Both types of absorptive capacity complement other organizational factors to improve the firm's ability to utilize knowledge. IT helps firms to develop both internal and external absorptive capacity by increasing overall knowledge base. Next, we conceptualize Closed Innovation through IT and Open Innovation through IT building on prior research.

\subsection{Closed Innovation through IT and Open Innovation through IT}

Innovation can take place in two ways -- within the boundary or beyond the boundary of a firm [30]. First, firms can take an internal approach to innovation where firms innovate by acquiring, processing, integrating, and leveraging internal knowledge and resources [30]. Second, learning from partner firms or relational ties and tapping on knowledge residing in the external environment is a critical source for innovation [31]. Firms can thus have an external approach to innovation by acquiring and processing knowledge and resources from external partners and integrating it with their own knowledge and resources to build innovations [1].

Accordingly, we distinguish between two approaches of using IT for innovation. First, we define Closed Innovation through IT as the extent to which the firm's internal information systems promote innovation inside the firm. Firms using the Closed Innovation through IT approach deploy IT to acquire and integrate internal knowledge and resources. Second, we define Open Innovation through IT as the extent to which the firm uses IT to collaborate for innovation with the firm's external constituents such as market leaders, suppliers, competitors, and clients. We next discuss the two salient deficiencies for innovation in small and medium enterprises that this study addresses.

\subsection{Deficiencies for Innovation in Small and Medium Enterprises}

Technological capability plays an important role in facilitating firm innovation. Technological capability enhances organizations' ability to utilize different resources, while increasing a firm's internal absorptive capacity for innovation [32]. Better utilization of resources in research and development enhances organizations' efficiency and effectiveness for new product development.

Government support for innovation can result in benefits for firms. Government support for firms can be in the form of tax incentives, grants, statesponsored labs, or direct investment by means of public venture capital, and it can directly influence firm's R\&D and innovation in both products and services. Government support can also provide crucial knowledge, training, resources and patronage to a variety of industries such as aircraft, energy, space and electronics. Thus, government support enables firms to enhance their internal abilities through additional means, termed as additionalities [21]. 


\subsection{Overcoming Technological Deficiency}

Technological deficiency refers to the extent to which a firm lacks technological abilities such as technological information, staff technological capabilities, and advanced technologies [20]. Examples of such technological abilities include product or engineering designs. We theorize that Closed Innovation through IT has a stronger effect than Open Innovation through IT in overcoming technological deficiency for two reasons.

First, due to technological deficiency, a firm may lack an ability to combine and recombine its internal resources for innovation. By using Closed Innovation through IT (e.g., internal knowledge management systems), the firm can develop internal absorptive capacity by forming linkages between internal knowledge sources in distributed teams, thereby overcoming detrimental effects of the firm's technological deficiency on innovation [29].

On the other hand, Open Innovation through IT is externally focused (e.g., information sharing via interorganizational supply chain management systems) [33]. Hence, Open Innovation through IT is less useful for firms that have technological deficiency and thus have not developed their internal absorptive capacity, since internal recombination of knowledge is critical for leveraging external knowledge obtained through Open Innovation through IT.

Second, Closed Innovation through IT facilitates sharing of knowledge and information across crossfunctional teams, thereby overcoming deleterious effects of technological deficiency [34]. Thus, Closed Innovation through IT fosters the development of internal absorptive capacity in the form of knowledge sharing [29].

In contrast, Open Innovation through IT focuses on developing innovations in partnership with external constituents and on exchanging knowledge with partners [35]. Hence, Open Innovation through IT is less effective than Closed Innovation through IT in overcoming the deleterious effect of technological deficiencies within the firm. Hence, we hypothesize:

H1: Closed Innovation through IT has a stronger attenuating effect than Open Innovation through $I T$ on the negative relationship between technological deficiency and innovation.

\subsection{Overcoming Government Support Deficiency}

Government support promotes innovation in a firm through input additionality and behavioral additionality. Input additionality refers to how government support through programs such as subsidies, funding, or firm-government research alliances enhance a firm's own innovation efforts [21]. Behavioral additionality refers to the effects of government support and policy interventions in facilitating adaptation or change of a "firm's innovation processes, routines, activities, or relevant corporate business / technology strategies, thereby facilitating the conversion of innovation inputs into outcomes" [21]. We theorize that when a firm has insufficient government support, the firm can mitigate this deficiency by using Open Innovation through IT to support innovation through collaborations with its external partners for two reasons.

First, Open Innovation through IT increases external absorptive capacity by facilitating collaboration with external constituents such as partners, suppliers, and customers, thereby enhancing the firm's knowledge pool $[28,33,36]$. By increasing the knowledge pool, Open Innovation through IT serves to supplement input additionality, overcoming the void left by government support deficiency with regard to input additionality.

In contrast, Closed Innovation through IT focuses on the integration and recombination of the firm's existing knowledge without going beyond the boundary of the firm. Hence, Closed Innovation through IT is ineffectual in helping the firm develop external absorptive capacity, which may supplement input additionality. Therefore, Closed Innovation through IT is less effective than Open Innovation through IT in overcoming government support deficiency.

Second, Open Innovation through IT fuels a flow of information and interactions between the firm and its external constituents through IT-based collaboration linkages and helps the firm to develop external absorptive capacity [28]. By increasing the firm's external absorptive capacity, Open Innovation through IT helps the firm to find alternative means to supplement its internal innovation abilities. This helps the focal firm to overcome the void left by government support deficiency with regard to behavioral additionality.

In comparison, since Closed Innovation through IT does not transcend a firm's boundaries, it is ineffectual in identifying opportunities or improvements. Hence, Closed Innovation through IT does not provide external absorptive capacity that may supplement behavioral additionality. Therefore, Closed Innovation through IT is less effective than Open Innovation through IT in overcoming government support deficiency. Hence, we hypothesize: 
H2: Open Innovation through IT has a stronger attenuating effect than Closed Innovation through IT on the negative relationship between government support deficiency and innovation.

\section{Method}

\subsection{Sampling and Data Collection}

To test our hypotheses, we use data collected from small and medium enterprises in Mexico. Small and medium enterprises in Mexico face challenges, both with respect to innovation as well as technological capabilities. Small and medium enterprises in Mexico widely use IT to improve their business and overcome operational challenges. Therefore, Mexican small and medium enterprises serve as a suitable context.

In Mexico, small and medium enterprises are defined as firms with less than 250 employees. To minimize confounding factors due to state-level differences, we developed a sample of 389 small and medium enterprises from the state of Jalisco in Mexico. These small and medium enterprises were randomly selected from a list of manufacturing small and medium enterprises provided by the Mexican Statistics Bureau (INEGI), which is an arm of the government (similar to U.S. Census Bureau). The sample is representative of the population of small and medium enterprises across the country. The sample was distributed across the entire state of Jalisco which has 125 municipalities (a municipality is the equivalent of a county). The selected small and medium enterprises were in industries such as high technology, food, automobile, fashion and design, and plastics, which are the main industries in Mexico.

The questionnaire was developed by operationalizing constructs that utilized existing scales where available or by adapting prior scales. The backtranslation method, pre-tests and a pilot test were used to create the final version of the questionnaire. The data were collected as part of a government-funded initiative by a government-affiliated institution. Interviewers were recruited and trained by INEGI to conduct surveys on site, which is an effective method to collect information in emerging economies [37, 38]. The interviewers visited the small and medium enterprise's premises, identified themselves with government-supported credentials, provided the survey, clarified any questions, and collected the completed survey. The small and medium enterprises were assured of the neutrality of the interviewers, confidentiality of responses, and importance of their participation. The small and medium enterprises also had a legal obligation to provide correct information and documentation to support their responses, resulting in a $100 \%$ response rate.

For each small and medium enterprise, the seniormost manager was the key respondent. In-depth interviews and pilot study conducted prior to the survey revealed that senior managers know most about IT-related strategies, innovation, and challenges faced by the small and medium enterprise. Hence, senior managers are suitable as respondents for the survey. The senior managers had to provide documentary evidence for several responses such as organizational outcomes and technological capabilities. Thus, single responder bias is not a significant concern because the responses were supported by documentation and were not subject to the cognitive and memory bias of the individual respondent.

For the 389 small and medium enterprises, the respondents had, on average, worked 10.5 years in the industry and 7.3 years with their firms. We conducted Harman's one-factor test on all variables in our data. There were three factors with eigenvalues greater than 1 , and the first factor accounted for only $24.29 \%$ percent of the variance, suggesting that common method bias is not a major concern.

In sum, as discussed above, the meticulous steps in design and execution of the survey substantially mitigate concerns of single-responder or common method bias in the following four ways: 1) survey responses were mandated by law and the survey was conducted in-person by interviewers with government-supported credentials; 2) respondents were required to provide documentary evidence for their responses; and 3) Harman's one-factor test provided multiple factors with no single major factor. For these reasons, the key informant approach is accurate, valid and appropriate.

\subsection{Variables}

Our measures were adapted from existing studies whenever possible, except when existing measures were not available. Every measure, except when indicated otherwise, used Likert-type scales.

Innovation: The innovation measure is based on prior studies [39, 40]. The measure consists of four items that capture the number of innovations by the small and medium enterprise in products, manufacturing processes, markets (commercialization), and administrative processes. To build a measure that reflects the small and medium enterprise's total innovation, we summed the four items in the measure. Since our focus is on small and medium enterprises, our measure is more appropriate than patent-based measures, as patent applications are 
prohibitively time consuming and expensive for typical small and medium enterprises in Mexico.

Technological Deficiency: This measure reflects the degree to which a firm lacks technological capability, and consists of five items that capture lack of technological information, technological capabilities, training, opportunities, and resistance to technology.

Government Support Deficiency: The measure comes from prior studies [41, 42] and comprises four items that capture the extent to which the government has not provided the small and medium enterprise with support for information, import, finance and legal aspects of new technology.

Closed Innovation through IT: The measure of Closed Innovation through IT is based on prior conceptual work [43, 44] and has three items that capture promotion of innovation within the firm, by information systems.

Open Innovation through IT: The measure, adapted from prior research [45] consists of four items which capture the extent to which the firm uses IT for innovation collaboration with market leaders, competitors, clients, and suppliers.

Control Variables: We include a number of control variables that account for several sources of heterogeneity. First, we measure R\&D expenses by percentage of sales dedicated to R\&D by the firm [46]. We control for firm size, measured by the logarithm of the number of employees [46]. We use four dummy variables to account for differences in the primary industry in which the small and medium enterprise operates. We control for the firm's annual sales. We also control for ownership, measured as a dummy variable to classify national and foreign firms [47]. We use a dummy variable to control for non-metropolitan and metropolitan location of the small and medium enterprise. Finally, we control for the effects of corruption, which is captured through an item in the survey which indicates the extent to which corruption hampers business operations.

\subsection{Construct Validity}

To assess the validity and adequacy of the multiple-item measures, we adapted a two-step approach. First, we conducted exploratory factor analyses, which generated the theoretically expected factor solutions, with generally high loadings (above 0.70 ) and low cross-loadings (below 0.30). All factors exhibited sufficient construct reliability, with Cronbach's alphas above the minimum recommended thresholds (above 0.80). Second, we conducted a confirmatory factor analysis. Composite reliability of all the constructs was above the 0.70 benchmark, demonstrating satisfactory internal consistency reliability. Depending on the nature of the construct, we assessed convergent and discriminant validity either by examining item loadings and the average variance extracted for constructs, or the weight, sign and magnitude of the items. Item loadings on their related theoretical constructs were significant and exceeded the recommended 0.70 threshold. The average variance extracted of every construct also higher than the 0.50 benchmark. Though a couple of items did not meet the thresholds, as recommended in prior research, they were retained to preserve content validity and ensure that the entire domain of the construct was measured. These assessments indicated that the measures demonstrate satisfactory convergent and discriminant validity. Overall, the results showed that our measures possess satisfactory validity and reliability.

We relied on root mean square error of approximation (RMSEA), incremental fit index (IFI), and comparative fit index (CFI) to assess the model fit. The fit indexes were above the common thresholds, $\mathrm{RMSEA}=0.078, \mathrm{IFI}=0.93$, and $\mathrm{CFI}=0.93$. Thus, the model fits the data satisfactorily. In line with the literature, we used factor scores obtained from confirmatory factor analysis as composite measures of Technological deficiency, Government Support deficiency, Closed Innovation through IT, and Open Innovation through IT [20].

\section{Analysis and Results}

\subsection{Econometric Estimation Results}

Our dependent variable is total number of innovations, which is a count variable that can have only discrete non-negative integer values. Hence, we use count regression models to test our hypotheses. Tests for over-dispersion in the distribution of the variable indicated no over-dispersion in the residuals and hence we estimated the models using Poisson regression. We also used standard errors that are robust to misspecifications. To deal with possible multicollinearity between interaction terms, we meancentered the interaction terms. As the highest variance inflation factors was less than 3.3, multicollinearity is not a major concern.

Table 1 shows the Poisson estimation results. Although we do not formally hypothesize the main effects of Government Support Deficiency and Technological Deficiency on innovation, we report these coefficients. In Model 1, coefficients of Technological Deficiency $(\beta=-0.20, \mathrm{p}<0.01)$ and Government Support Deficiency $(\beta=-0.12, \mathrm{p}<0.05)$ are negative and significant, consistent with our 
expectation that these deficiencies have an adverse effect on innovation. H1 posited that Closed Innovation through IT has a stronger attenuating effect than Open Innovation through IT on the negative relationship between Technological Deficiency and Innovation. In Model 2, coefficient of interaction of Closed Innovation through IT with Technological Deficiency is positive and significant $(\beta=0.12, \mathrm{p}<$ 0.01 ), whereas the coefficient of interaction of Open Innovation through IT with Technological Deficiency is not significant $(\mathrm{p}=\mathrm{ns})$. Hence, hypothesis $\mathrm{H} 1$ is supported.

Table 1. Results

\begin{tabular}{|l|c|c|}
\hline \multicolumn{1}{|c|}{ VARIABLES } & 1 & 2 \\
\hline Tech Deficiency & $-0.20 * * *$ & $-0.35^{* * *}$ \\
Gov Sup Deficiency & $(0.08)$ & $(0.11)$ \\
Closed Innovation & $\left(0.12^{* *}\right.$ & $-0.22^{* *}$ \\
through IT & $0.46^{* * *}$ & $0.49 * * *$ \\
Open Innovation & $(0.04)$ & $(0.04)$ \\
through IT & $0.66 * * *$ & $0.22^{* *}$ \\
Tech Def $\times$ Closed & $(0.25)$ & $(0.10)$ \\
Innovation through IT & & $0.12 * * *$ \\
Govt Sup Def $\times$ Open & & $(0.03)$ \\
Innovation through IT & & $0.82 * * *$ \\
Tech Def $\times$ Open & & $(0.31)$ \\
Innovation through IT & & 0.09 \\
Gov Sup Def $\times$ Closed & & $(0.08)$ \\
Innovation through IT & & $0.08 * *$ \\
Controls & & $(0.04)$ \\
Observations & & Yes \\
$\mathrm{R}^{2}$ & 389 & 389 \\
& & 0.20 \\
\hline
\end{tabular}

$\mathrm{H} 2$ posited that Open Innovation through IT has a stronger attenuating effect than Closed Innovation through IT on the negative relationship between Government Support Deficiency and Innovation. In Model 2, the coefficient of interaction of Open Innovation through IT with Government Support Deficiency is positive and significant $(\beta=0.82, \mathrm{p}<$ 0.01 ), and the coefficient of interaction of Closed Innovation through IT with Government Support Deficiency is positive and significant $(\beta=0.08, \mathrm{p}<$ $0.05)$. Hence, hypothesis $\mathrm{H} 2$ is supported.

\subsection{Tests for Endogeneity}

We conduct a robustness analysis to account for the possibility that Open Innovation through IT and Closed Innovation through IT can be endogenous by using a two-step econometric procedure proposed by Heckman [48]. Results suggest a lack of bias due to endogeneity and are similar to the main results. Details of the analysis are omitted for brevity.

\section{Discussion}

\subsection{Findings}

The objective of this study was to explore how Open Innovation through IT and Closed Innovation through IT help overcome the adverse effects of technological deficiency and government support deficiency for innovation. We obtain two main findings. First, Closed Innovation through IT has a stronger attenuating effect than Open Innovation through IT on the negative relationship between technological deficiency and innovation. This supports our argument that Closed Innovation through IT promotes the development of internal absorptive capacity through superior knowledge sharing practices in the firm, and hence is more important than Open Innovation through IT for overcoming insufficiency in technological ability.

Second, Open Innovation through IT has a stronger attenuating effect than Closed Innovation through IT on the negative relationship between government support deficiency and innovation. This is corroborates our rationale that Open Innovation through IT helps firms to better leverage resources and information from their partners, which helps them to overcome the lack of external assistance provided by the government.

Although not formally hypothesized, the main effects of technological deficiency and government support deficiency on innovation are negative and significant in the regression models. This is consistent with our expectations and lends validity to our theoretical arguments, empirical setup, and data. Our additional analysis suggests that Closed Innovation through IT can also help firms to overcome the challenge of being in a non-metropolitan geographical location. Our findings are robust to endogeneity and consistent with other robustness tests.

\subsection{Theoretical Contributions}

Our study makes two theoretical contributions. First, we address a tension regarding Closed 
Innovation through IT and Open Innovation through $I T$ by showing that they differ in the extent to which they help small and medium enterprises mitigate effects of technological deficiency and government support deficiency on innovation. Prior innovation literature does not provide prescriptive guidance on the type of IT-enabled approach to follow to overcome deficiencies. Our study suggests that while Open Innovation through IT addresses additionalities and thereby helps firms develop external absorptive capacity, Closed Innovation through IT helps with development of internal absorptive capacity by acquiring and integrating internal knowledge and resources.

Second, this study is among the first to highlight that IT can overcome deficiencies in government support, thereby extending IT and innovation literature to the institutional context related to government support for innovation. There has been scant attention to how IT overcomes deficiencies in the institutional environment, such as government support deficiency. More generally, our study is among the first to examine how IT attenuates negative effects of deficiencies on innovation.

More generally, this research adds to the growing research that examines phenomena in developing economies and under-developed areas of developed economies. For example, GREAT (growing, rural, eastern, aspirational, and transitional) domains [22] serve as a setting for an increasing number of research studies [37, 38, 47, 49-51]. Given the rich histories [52] and large sizes of these domains, such investigations not only add to the theoretical multiplicity of our literature [22], but also address problems with large impact [53].

\subsection{Managerial Implications}

Our study has two key managerial contributions. First, small and medium enterprises achieve greater innovation returns by orienting their IT-enabled innovation efforts in an open or closed collaboration fashion to address the specific deficiency the small and medium enterprise faces. Managers of small and medium enterprises need to carefully evaluate the source of innovation deficiencies and focus their ITenabled innovation efforts accordingly. Small and medium enterprise managers should emphasize on using IT in a closed innovation manner if they face technological deficiency. In such cases, small and medium enterprises would be better off by concentrating their IT efforts on promoting and supporting innovation within the firm.

In contrast, if the small and medium enterprise is hindered by government support deficiency, then small and medium enterprises should give preference to using IT for open innovation to collaborate with external constituents such as customers and suppliers. Ergo, firms that use IT for innovation in a manner aligned with the type of deficiency they face are more likely to achieve innovation.

Second, since open innovation has garnered significant attention due in part to the emergence of advanced digital platforms (e.g., crowdsourcing and open innovation challenges), managers tend to be excessively upbeat towards use of open innovation. Our findings indicate that both open and closed forms of IT-enabled innovation have value. We exhort managers not to disregard either form of innovation, but rather to tailor their IT-enabled innovation approaches to suit their organizational context in terms of the specific deficiency the firm faces. An implication for managers is that they need to periodically evaluate their firm's technological deficiency and government support deficiency and take steps to orient their IT-enabled innovation approaches accordingly. These steps can involve inculcating an organizational culture that emphasizes open and closed approaches to IT-enabled innovation.

\subsection{Limitations and Conclusion}

We acknowledge limitations of our study. First, our sample consists of small and medium enterprises from a single country (Mexico). Although focusing on a single country enhances internal reliability and avoids issues arising from cross-country heterogeneity, we can only theoretically claim but are unable to empirically demonstrate generalizability to other countries.

Second, the cross-sectional nature of our dataset precludes us from drawing categorically causal conclusions. Since our study is focused on small and medium enterprises on which there are no known and reliable secondary longitudinal data sources related to IT-enabled innovation, it is not feasible for us to prove strictly causal relationships in this context. Although our analysis leverages two-stage models to account for potential endogeneity to address this issue consistent with prior studies, it presents an interesting avenue for future research.

In conclusion, our study provides important insights for how small and medium enterprises can use IT in an externally collaborative and internally collaborative approach to achieve innovation, a critical means for development in emerging economies. Due to their contribution to employment generation, small and medium enterprises are the growth engine of emerging economies and their innovation plays an essential role in the economic and social development. 


\section{References}

[1] H. W. Chesbrough, Open innovation: The new imperative for creating and profiting from technology. Harvard Business Press, 2003.

[2] P. Karhade and J. Dong, "Innovation Outcomes of Digitally Enabled Collaborative Problemistic Search Capability," MIS Quarterly, forthcoming.

[3] P. Karhade and J. Dong, "Information Technology Investment and Commercialized Innovation Performance: Dynamic Adjustment Costs and Curvilinear Impacts," MIS Quarterly, forthcoming.

[4] T. Saldanha, A. Sahaym, S. Mithas, M. Andrade Rojas, A. Kathuria, and H.-H. Lee, "Turning Liabilities of Global Operations into Assets: IT-enabled Social Integration Capacity and Exploratory Innovation," Information Systems Research, vol. 31, no. 2, pp. 361$382,2020$.

[5] E. Bendoly, E. Rosenzweig, and J. Stratman, "The efficient use of enterprise information for strategic advantage: A data envelopment analysis," Journal of Operations Management, vol. 27, no. 4, 2009.

[6] P. P. Tallon, "A process-oriented perspective on the alignment of information technology and business strategy," Journal of Management Information Systems, vol. 24, no. 3, pp. 227-268, 2007.

[7] J. Dedrick, V. Gurbaxani, and K. L. Kraemer, "Information technology and economic performance: A critical review of the empirical evidence," $A C M$ Computing Surveys, vol. 35, no. 1, pp. 1-28, 2003.

[8] S. Devaraj, L. Krajewski, and J. C. Wei, "Impact of eBusiness technologies on operational performance: the role of production information integration in the supply chain," Journal of Operations Management, vol. 25, no. 6, pp. 1199-1216, 2007.

[9] L. Kleis, P. Chwelos, R. V. Ramirez, and I. Cockburn, "Information technology and intangible output: The impact of IT investment on innovation productivity," Information Systems Research, vol. 23, no. 1, pp. 4259, 2012.

[10] S. Chatterjee, G. Moody, P. B. Lowry, S. Chakraborty, and A. Hardin, "Strategic Relevance of Organizational Virtues Enabled by Information Technology in Organizational Innovation," Journal of Management Information Systems, vol. 32, no. 3, pp. 158-196, 2015.

[11] J. Gómez, I. Salazar, and P. Vargas, "Does Information Technology Improve Open Innovation Performance? An Examination of Manufacturers in Spain," Information Systems Research, vol. 28, no. 3, 2017.

[12] T. Ravichandran, S. Han, and S. Mithas, "Mitigating diminishing returns to R\&D: The role of information technology in innovation," Information Systems Research, vol. 28, p. 4, 2017.

[13] T. J. Saldanha, A. Sahaym, S. Mithas, M. Andrade Rojas, A. Kathuria, and H.-H. Lee, "Turning Liabilities of Global Operations into Assets: IT-enabled Social Integration Capacity and Exploratory Innovation," Information Systems Research, forthcoming.

[14] S. Nambisan, "Information systems as a reference discipline for new product development," MIS Quarterly, vol. 27, no. 1, pp. 1-18, 2003.
[15] A. Majchrzak and A. Malhotra, "Effect of knowledgesharing trajectories on innovative outcomes in temporary online crowds," Information Systems Research, vol. 27, no. 4, pp. 685-703, 2016.

[16] P. Tambe, L. M. Hitt, and E. Brynjolfsson, "The extroverted firm: How external information practices affect innovation and productivity," Management Science, vol. 58, no. 5, pp. 843-859, 2012.

[17] T. Saldanha, S. Mithas, and M. Krishnan, "Leveraging Customer Involvement for Fueling Innovation: The Role of Relational and Analytical Information Processing Capabilities," MIS Quarterly, vol. 41, no. 1, pp. 267-286, 2017.

[18] J. Ettlie and P. Pavlou, "Technology-based new product development partnerships," Decision Sciences, vol. 37, no. 2, 2006.

[19] K. Trantopoulos, G. von Krogh, M. Wallin, and M. Woerter, "External knowledge and information technology: Implications for process innovation performance," MIS Quarterly, vol. 41, no. 1, pp. 287300, 2017.

[20] K. Z. Zhou and F. Wu, "Technological capability, strategic flexibility, and product innovation," Strategic Management Journal, vol. 31, no. 5, pp. 547-561, 2010.

[21] M. Rojas, E. Solis, and J. Zhu, "Innovation and network multiplexity: R\&D and the concurrent effects of two collaboration networks in an emerging economy," Research Policy, vol. 47, no. 6, p. 1111, 2018.

[22] P. Karhade and A. Kathuria, "Missing Impact of Ratings on Platform Participation in India: A Call for Research in G. R. E. A. T. Domains," Communications of the Assoc. for Info. Sys., vol. 47, 2020.

[23] M. G. Andrade Rojas, S. Y. Li, and J. J. Zhu, "Social Innovation in Emerging Economies: An Ecosystem Built on Collaboration and Knowledge Sharing," in Academy of Management Proceedings, 2018, vol. 2018, no. 1: Academy of Management, Briarcliff Manor, NY 10510, p. 15893.

[24] S. Devaraj and R. Kohli, "Performance impacts of information technology: Is actual usage the missing link?," Management Science, vol. 49, no. 3, pp. 273289, 2003.

[25] L. Kleis, P. Chwelos, R. Ramirez, and I. Cockburn, "Information technology and intangible output: The impact of IT investment on innovation productivity," Information Systems Research., vol. 23, no. 1, 2012.

[26] T. Ravichandran, S. Han, and S. Mithas, "Mitigating diminishing returns to R\&D: The role of information technology in innovation," Information Systems Research, vol. 28, no. 4, pp. 812-827, 2017.

[27] A. Majchrzak and A. Malhotra, "Towards an information systems perspective and research agenda on crowdsourcing for innovation," Journal of Strategic Information Systems, vol. 22, no. 4, p. 257, 2013.

[28] A. Lewin, S. Massini, and C. Peeters, "Microfoundations of internal and external absorptive capacity routines," Organization Science, vol. 22, no. 1, pp. 81-98, 2011.

[29] K. Joshi, L. Chi, A. Datta, and S. Han, "Changing the competitive landscape: Continuous innovation through 
IT-enabled knowledge capabilities," Information Systems Research, vol. 21, no. 3, 2010.

[30] T. Felin and T. R. Zenger, "Closed or open innovation? Problem solving and the governance choice," Research Policy, vol. 43, no. 5, pp. 914-925, 2014.

[31] W. Powell, K. Koput, and L. Smith-Doerr, "Interorganizational collaboration and the locus of innovation: Networks of learning in biotechnology," Administrative Science Quarterly, vol. 41, 1, p. 116, 1996.

[32] D. Lavie and L. Rosenkopf, "Balancing exploration and exploitation in alliance formation," Academy of Management Journal, vol. 49, no. 4, pp. 797-818, 2006.

[33] M. G. Andrade Rojas and A. Kathuria, "Competitive Brokerage: External Resource Endowment and Information Technology as Antecedents," in Academy of Management Proceedings, 2014, vol. 2014, no. 1: Academy of Management,Briarcliff Manor, NY 10510, p. 15643.

[34] M. G. Andrade Rojas, A. Kathuria, and H.-H. Lee, "Attaining Operating Performance through Pas De Trios of IT, Competitive Brokerage and Innovation," in International Conference on Information Systems, 2015.

[35] K. Han, W. Oh, K. S. Im, R. M. Chang, H. Oh, and A. Pinsonneault, "Value cocreation and wealth spillover in open innovation alliances," MIS Quarterly, pp. 291$315,2012$.

[36] M. Andrade Rojas and A. Kathuria, "Competitive brokerage, information technology and internal resources," in International Conference on Information Systems, 2014.

[37] A. Kathuria, A. Mann, J. Khuntia, T. Saldanha, and R. Kauffman, "A strategic value appropriation path for cloud computing," Journal of Management Information Systems, vol. 35, no. 3, 2018.

[38] J. Khuntia, A. Kathuria, T. Saldanha, and B. Konsynski, "Benefits of IT-Enabled Flexibilities for Foreign versus Local Firms in Emerging Economies," Journal of Management Information Systems, vol. 36, no. 3, p. 855, 2019.

[39] Z.-L. He and P.-K. Wong, "Exploration vs. exploitation: An empirical test of the ambidexterity hypothesis," Organization Science, vol. 15, no. 4, pp. 481-494, 2004.

[40] J. Jansen, F. Van Den Bosch, and H. Volberda, "Exploratory Innovation, Exploitative Innovation, and Performance: Effects of Organizational Antecedents and Environmental Moderators," Management Science, vol. 52, no. 11, pp. 1661-1674, 2006.

[41] H. Li and K. Atuahene-Gima, "Product innovation strategy and the performance of new technology ventures in China," Academy of Management Journal, vol. 44, no. 6, pp. 1123-1134, 2001.

[42] C. Shu, K. Zhou, Y. Xiao, and S. Gao, "How green management influences product innovation in China: The role of institutional benefits," Journal of Business Ethics, vol. 133, no. 3, pp. 471-485, 2016.

[43] D. A. Marchand, W. J. Kettinger, and J. D. Rollins, "Information orientation: people, technology and the bottom line," Sloan Management Review, vol. 41, no. 4, pp. 69-80, 2000.

[44] M. Zárraga-Rodríguez and M. J. Alvarez, "Exploring the links between information capability and the EFQM business excellence model: the case of Basque Country Quality award winners," Total Quality Management \& Business Excellence, vol. 24, no. 5-6, pp. 539-560, 2013.

[45] D. R. Gnyawali and B.-J. R. Park, "Co-opetition between giants: Collaboration with competitors for technological innovation," Research Policy, vol. 40, no. 5, pp. 650-663, 2011.

[46] T. Saldanha, A. Kathuria, J. Khuntia, and B. Konsynski, "Ghosts in the Machine: How Marketing and Human Capital Investments Enhance Customer Growth when Innovative Services Leverage Self-Service Technologies," Information Systems Research, forthcoming.

[47] A. Kathuria and B. R. Konsynski, "Juggling Paradoxical Strategies: The Emergent Role of IT Capabilities," in Thirty Third International Conference on Information Systems, Orlando, FL, 2012: Association for Information Systems.

[48] J. J. Heckman, "Sample Selection Bias as a Specification Error," Econometrica, vol. 47, no. 1, pp. 153-161, 1979.

[49] A. Kathuria, P. P. Karhade, and B. R. Konsynski, "In the Realm of Hungry Ghosts: Multi-Level Theory for Supplier Participation on Digital Platforms," Journal of Management Information Systems, vol. 37, no. 2, pp. 396-430, 2020.

[50] R. Kathuria, N. N. Kathuria, and A. Kathuria, "Mutually supportive or trade-offs: An analysis of competitive priorities in the emerging economy of India," The Journal of High Technology Management Research, vol. 29, no. 2, pp. 227-236, 2018.

[51] J. Khuntia, A. Kathuria, M. Andrade Rojas, T. Saldanha, and N. Celly, "How Foreign and Domestic Firms Differ in Leveraging IT-enabled Supply Chain Information Integration in BOP Markets: The Role of Supplier and Client Business Collaboration," Journal of the Association for Information Systems, forthcoming.

[52] N. Celly, A. Kathuria, and V. Subramanian, "Overview of Indian multinationals," in Emerging Indian Multinationals: Strategic Players in a Multipolar World, 2016.

[53] S. Nambisan, "Information Technology and Product/Service Innovation: A Brief Assessment and Some Suggestions for Future Research," Journal of the Association for Information Systems, vol. 14, no. 4, 2013. 